\title{
WestVirginiaUniversity
}

THE RESEARCH REPOSITORY @ WVU

Graduate Theses, Dissertations, and Problem Reports

1999

\section{The effectiveness of prophylactic etodolac on post-endodontic pain}

\author{
Eric Richard Menke \\ West Virginia University
}

Follow this and additional works at: https://researchrepository.wvu.edu/etd

\section{Recommended Citation}

Menke, Eric Richard, "The effectiveness of prophylactic etodolac on post-endodontic pain" (1999).

Graduate Theses, Dissertations, and Problem Reports. 1060.

https://researchrepository.wvu.edu/etd/1060

This Thesis is protected by copyright and/or related rights. It has been brought to you by the The Research Repository @ WVU with permission from the rights-holder(s). You are free to use this Thesis in any way that is permitted by the copyright and related rights legislation that applies to your use. For other uses you must obtain permission from the rights-holder(s) directly, unless additional rights are indicated by a Creative Commons license in the record and/ or on the work itself. This Thesis has been accepted for inclusion in WVU Graduate Theses, Dissertations, and Problem Reports collection by an authorized administrator of The Research Repository @ WVU. For more information, please contact researchrepository@mail.wvu.edu. 


\title{
The Effectiveness of Prophylactic Etodolac
}

\section{On Post-Endodontic Pain}

\author{
Eric R. Menke, D.D.S.
}

Submitted to the School of Dentistry at West Virginia University in partial fulfillment of the requirements for the degree of

\section{Master of Science}

in

Endodontics

C. Russell Jackson, D.D.S., M.S., Chair Michael Bagby, D.D.S., PhD

Timothy Tracy, PhD

\section{Division of Endodontics}

Morgantown, West Virginia 1999

Keywords: Dentistry, Ibuprofen, Endodontics 
I would like to dedicate this research study to first and foremost my wife Christy. Thank you for always being there for me, helping me strive toward all of my goals, and being my best friend. I would also like to dedicate this study to my parents for giving me every opportunity one could ask for and always pushing me do my best. I love all of you and appreciate everything you have done for me. 


\section{ACKNOWLEDGMENTS}

I would like to take this opportunity to thank the following people:

Dr. C. Russell Jackson, for giving me the opportunity to become an endodontist. For making me feel comfortable in a new environment and always being understanding. Thank you for sharing all your wisdom in dentistry and other attributes of life.

Dr. Mike Bagby, for your time and effort in completing this project.

Dr. Tim Tracy, for your input and expertise. Go Reds!

Cathy Myers, for making dentistry fun and always making me laugh and Gina White, for all of your hard work.

Marcie Weimer, Kim Pratt, and Cindy Williams, for scheduling all of our patients and keeping our lives in order.

Dr. Jerry Hobbs, for all your help with the statistical data.

Jason Hales and Ted Stowe, for all of their help in Fairmont and Bruceton Mills.

Drs. Michael Nimmich, Corene Poelman, Cathy Connor, and Robert Raynes, for making the residency program enjoyable and educational.

Dr. Christopher Kayafas, for dealing with me the past two years and always keeping a positive attitude. I appreciate everything you did to make the residency as much fun as it was. You truly are a great friend! 


\section{TABLE OF CONTENTS}

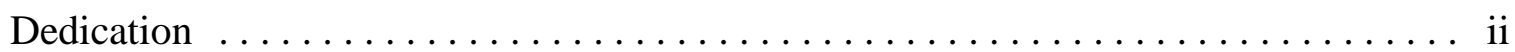

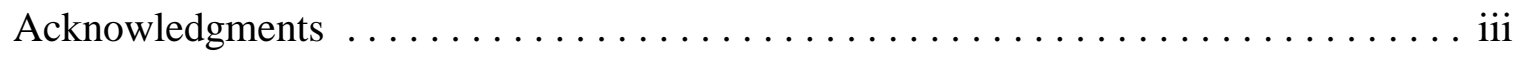

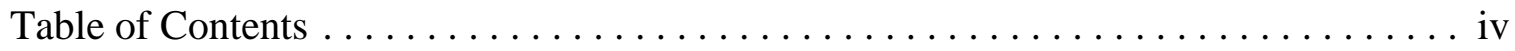

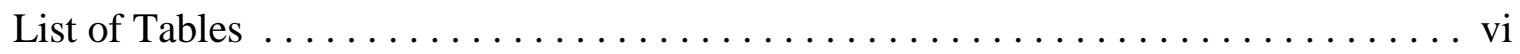

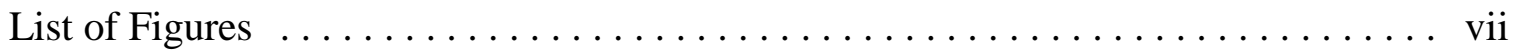

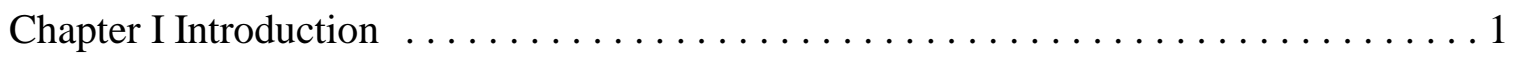

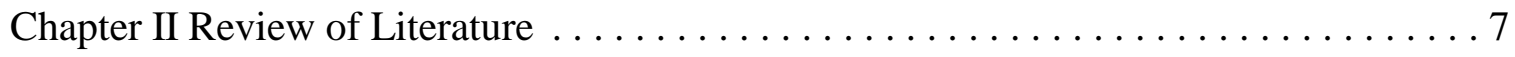

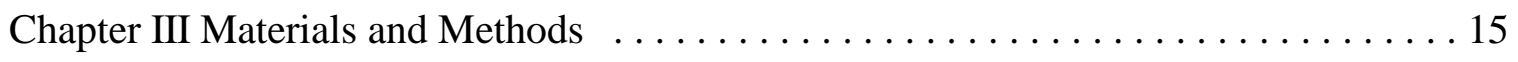

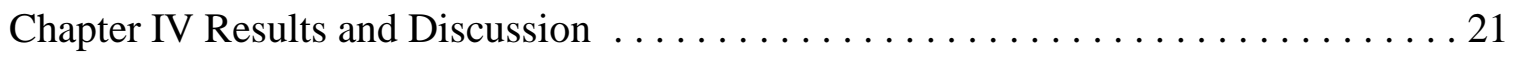

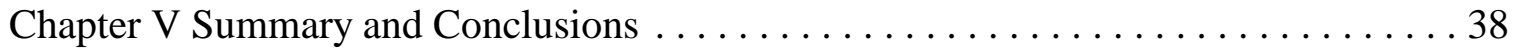

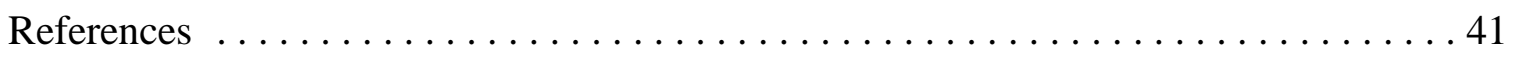

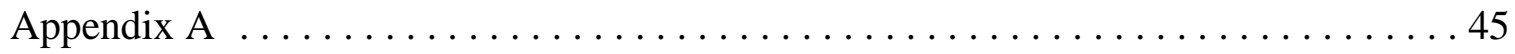

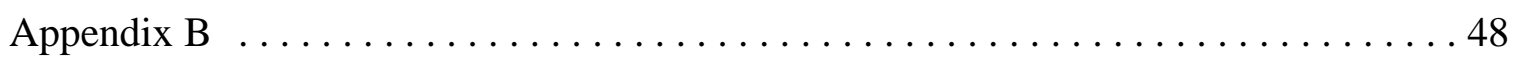

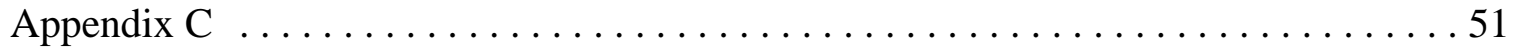

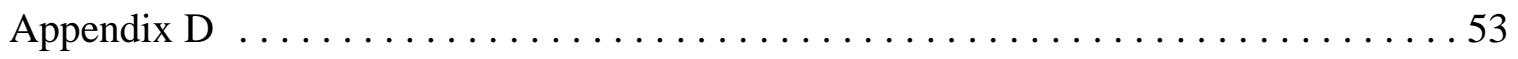

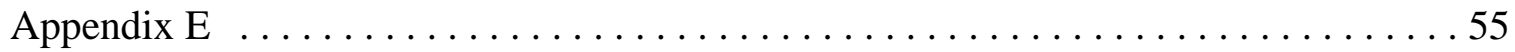

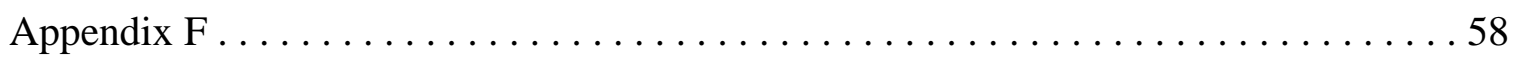

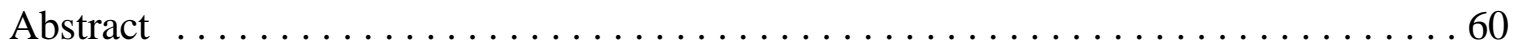




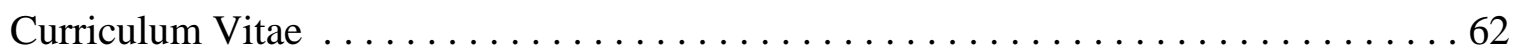




\section{LIST OF TABLES}

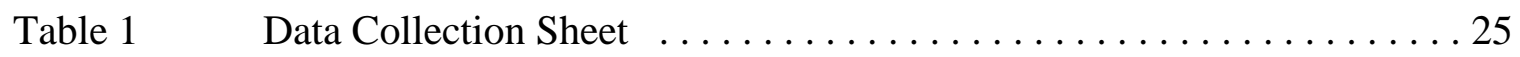

Table 2 Data Collection Sheet Legend $\ldots \ldots \ldots \ldots \ldots \ldots \ldots \ldots \ldots \ldots \ldots \ldots \ldots \ldots \ldots \ldots$

Table $3 \quad$ Means and Standard Deviations .................... 28

Table $4 \quad$ Periapical Diagnosis and Additional Medication . . . . . . . . . . . 29

Table $5 \quad$ Pulpal Diagnosis and Additional Medication $\ldots \ldots \ldots \ldots \ldots \ldots$

Table 6 Antibiotics Taken for Tooth and Additional Medication . . . . . . 33

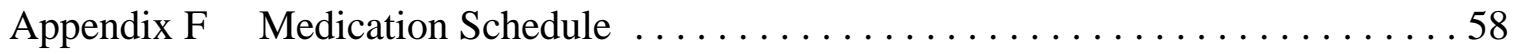




\section{LIST OF FIGURES}

Figure $1 \quad$ Experimental Medication and Pain Relief Over Time . . . . . . . . 27

Figure 2 Periapical Diagnosis and Additional Medication $\ldots \ldots \ldots \ldots \ldots$

Figure 3 Pulpal Diagnosis and Additional Medication $\ldots \ldots \ldots \ldots \ldots$

Figure $4 \quad$ Antibiotics Taken for Tooth and Additional Medication $\ldots . \ldots . .34$ 


\section{CHAPTER I}

\section{INTRODUCTION}

\section{BACKGROUND}

Endodontic therapy is widely thought of as being a painful experience (1). When most individuals seek root canal therapy, pain is already present. A significant relationship exists between pre-endodontic and post-endodontic pain. Patients with severe preoperative pain tend to have more severe operative and postoperative pain than patients with mild or no preoperative pain (2). Ideally, root canal therapy will eliminate post-endodontic pain but occasionally analgesics are needed to diminish the pain.

Inflammation is initiated by histamine, bradykinin, and prostaglandins (3).

Prostaglandins increase vascular permeability, raise chemotactic activity, induce fever, and increase sensitivity of pain receptors to other active inflammatory mediators (4).

Endodontic therapy produces local trauma and subsequent inflammation. Prostaglandins play a role in inflammation and may have a role in pain formation following endodontic therapy.

Nonsteroidal anti-inflammatory drugs inhibit prostaglandin synthesis by decreasing the activity of the enzyme, cyclo-oxygenase (5). In 1991, researchers discovered that the cyclo-oxygenase enzyme existed as two separate entities; Cox-1 and Cox-2. Cox-1 synthesizes protective prostaglandins, which preserve the integrity of the 
stomach lining and maintain normal renal function in a compromised kidney. Cox-2 is induced by pro-inflammatory cytokines and growth factors, which implies that Cox-2

plays a role in both inflammation and control of cell growth (6). The discovery of Cox-2 has made it possible for researchers to design drugs that reduce inflammation without removing the protective prostaglandins of the stomach and kidney.

Oral surgery models have shown preoperative administration of the nonsteroidal anti-inflammatory drugs ibuprofen or flurbiprofen suppress postoperative pain more effectively than a placebo, acetaminophen, or acetaminophen plus oxycodone $(7,8)$. Administration of a nonsteroidal anti-inflammatory drug prior to root canal therapy will interfere with the inflammatory process before it begins; therefore, decreasing postoperative pain.

Etodolac is a nonsteroidal anti-inflammatory drug that has been proven to be an effective analgesic for rheumatoid arthritis $(9,10)$ and post-operative pain management in oral surgery models $(11,12)$. Etodolac has also been proven to have a high affinity to block the Cox-2 enzyme $(13,14)$. The ability of etodolac to control post-endodontic pain, when administered prophylactically has not been analyzed. The goal of this study is to determine if prophylactic etodolac will significantly reduce post-endodontic pain, when compared to prophylactic ibuprofen, and when compared to a placebo.

\section{STATEMENT OF PROBLEM}

Etodolac possesses a high affinity to block the Cox- 2 enzyme, but will prophylactic etodolac significantly reduce post-endodontic pain, when compared to 
ibuprofen, and a placebo?

\section{SIGNIFICANCE OF STUDY}

After conventional root canal therapy, post-endodontic pain may occur. If prophylactic etodolac can significantly reduce post-endodontic pain, perhaps it should be implemented in the everyday protocol for root canal therapy.

\section{HYPOTHESIS}

The two hypotheses of this study are:

1. Prophylactic etodolac will significantly reduce post-endodontic pain when compared to ibuprofen and when compared to a placebo.

2. Prophylactic etodolac will significantly reduce post-endodontic pain regardless of the pulpal or periapical diagnosis.

\section{OPERATIONAL DEFINITIONS}

The following terms are defined for clarification:

Post-endodontic pain: Any pain that is perceived by the patient after root canal therapy (cleaning/shaping and/or obturation).

Etodolac: Nonsteroidal anti-inflammatory agent, which inhibits prostaglandin synthesis by decreasing the activity of the enzyme, cyclooxygenase, specifically Cox-2. The recommended dosage for acute pain is 200-400 mg every 6-8 hours, with the maximum daily dose being 
$1200 \mathrm{mg}$. Onset of action is 30 minutes. Duration of analgesic effect is 46 hours.

Ibuprofen: Nonsteroidal anti-inflammatory agent, which inhibits prostaglandin synthesis by decreasing the activity of the enzyme, cyclooxygenase, both Cox-1 and Cox-2. The recommended dosage for acute pain is $400-800 \mathrm{mg} 3-4$ times a day, with the maximum daily dose being $3200 \mathrm{mg}$. Onset of action is 30-60 minutes. Duration of analgesic effect is 4-6 hours.

Prophylactic Medication: Oral administration of a medication prior to root canal therapy.

Visual Analog Scale: A one-hundred millimeter horizontal line used to measure the patients perceived pain. Zero is the left extreme and it equals, "No pain." One-hundred is the right extreme and it equals, "Pain so severe you can't stand it."

Pulpal and Periapical Diagnosis: Determined for each patient by collecting data from the clinical exam and applying it to the flow charts in Appendix E.

\section{ASSUMPTIONS}

The only assumption in this study is that all endodontically treated teeth commonly produce post-endodontic pain at some level. 


\section{LIMITATIONS}

The following limitations apply to the overall study:

Pain will differ from individual to individual prior to and after root canal therapy.

Age differences will exist among the patients.

Gender differences will exist among the patients.

Health histories will differ among the patients.

Different teeth in the arch will be used.

Etodolac may affect patients differently.

Patient must return the pain survey in order for the data to be collected.

Endodontic diagnosis is not an exact science.

Some patients may be taking antibiotics for the involved tooth.

\section{DELIMITATIONS}

The following delimitations may apply to the overall study:

Diagnosis of each tooth will be determined and recorded. A particular pulpal or periapical diagnosis is not required to be considered for the study.

The patient must be 18 years or older.

A history of one of the following conditions will contraindicate the use of the patient for the study; mitral valve prolapse, rheumatic heart disease, artificial heart valves or joints, myocardial infarction, stroke, 
untreated hypertension, hyperthyroidism, hepatitis, epilepsy, bleeding disorders, stomach ulcers, kidney problems, liver problems, currently pregnant, or current use of medications contraindicated with NSAIDs. A patient will not be considered for evaluation if he/she has taken any type of pain medication within 6 hours of the scheduled root canal therapy. 


\section{CHAPTER II}

\section{REVIEW OF LITERATURE}

Root canal therapy is regarded by the public as being a painful experience. Surveys conducted by the American Association of Endodontists reveal that over half of the patients referred to endodontists are in pain (15). Most patients that endodontists treat are in pain prior to root canal therapy. Once treatment has been rendered, pain can still persist.

Certain preoperative clinical factors and some iatrogenic circumstances during treatment can predispose individuals to post-endodontic pain. Seltzer, Bender, and Ehrenreich treated 653 patients with a variety of intracanal medicaments during multivisit root canal therapy. $40 \%$ of the patients experienced pain after treatment. The incidence of pain was found to be significantly greater in patients with acute pulpitis or acute pericementitis (periodontitis) than patients with chronic pulpitis or chronic pericementitis (periodontitis). The stage of instrumentation (complete or incomplete) was not related to incidence or duration of pain. No difference was found in the incidence or severity of pain regardless of which pair of drugs were compared. Patients older than 21 years 
experienced more postoperative pain than younger patients (16).

O'Keefe concluded in 1976, that a significant relationship existed between preoperative, operative, and postoperative endodontic pain levels. Patients with severe postoperative pain tended to have more severe operative and postoperative pain than patients with mild or no preoperative pain. He also found posterior teeth were more likely to cause postoperative pain and patients older than 20 years of age experienced postoperative pain significantly more often than younger patients (2).

In 1970 Fox et., al., examined 291 one-visit root canal therapy procedures. They reported that tooth vitality did not have a significant effect on postoperative pain. However, they did conclude that teeth without radiolucent apical areas were associated with more postoperative pain than those with an apical radiolucency. They also found that females were more susceptible to postoperative pain than males (17).

Genet, et., al., evaluated preoperative and operative factors and their association with the incidence of postoperative pain after the first session of root canal treatment. A positive correlation occurred with postoperative pain and the following factors: 1) the presence of preoperative pain in conjunction with a non-vital pulp; 2) the presence of a radiolucency larger than $5 \mathrm{~mm}$ in diameter; 3 ) the number of canals in the treated tooth; and 4) women reported more postoperative pain than men (18).

Harrison, Baumgartner, and Svec published two reports dealing with the incidence of pain associated with endodontic treatment. The first study found that the degree of pain remained constant regardless of whether the teeth were; vital or non-vital; previously opened or intact; single rooted or multirooted; anterior or posterior; maxillary or 
mandibular. The second paper reported the following; 1) postfilling pain would most likely occur within 24 hours after filling, or not at all; 2) pain was not associated with the preoperative condition; 3) if patients had pain during treatment there was an increased likelihood of postfilling pain; and 4) less pain occurred in patients who were irrigated with $3 \%$ hydrogen peroxide and $5.25 \%$ sodium hypochlorite and medicated with formocresol $(19,20)$.

In summary, some studies found that certain preoperative characteristics lead to postoperative pain, while others found that those same characteristics have no effect on postoperative pain. Genet found that a radiolucency of $5 \mathrm{~mm}$ or greater produced postoperative pain in multivisit root canal therapy, while Fox found that a radiolucency was less likely to cause postoperative pain in one visit root canal therapy. Preoperative conditions may assist the practitioner in determining if the patient will experience postoperative pain but other factors can also produce post-endodontic pain.

Certain iatrogenic circumstances can lead to post-endodontic pain. The operator can induce post-endodontic pain by extruding debris, instruments, paper points, filling materials, or disinfectant outside of the canal and into the periapical tissues (21). Unfortunately these situations are sometimes unavoidable and result in post-endodontic pain.

The number of office visits required to complete root canal therapy has been continually argued. The incidence of postoperative pain between one-visit endodontics and multiple-visit endodontics has been explored. Fox, et., al., evaluated postoperative pain in 247 teeth following complete, one-visit endodontic treatment. Within 24 hours 
following treatment, $90 \%$ of the patients showed little or no spontaneous pain and $82 \%$ had little or no percussion sensitivity (17). Morse, et., al., studied 200 cases and found 98.5\% of the patients showed no or slight pain after one appointment root canal therapy (22). In 1982, Mulhern et., al., concluded that no difference existed in postoperative pain and the number of visits required to complete the root canal procedure (23). From these conclusions, the root canal therapy procedures completed in this study were performed in one visit, if time allowed.

Ideally, root canal therapy would eliminate all pain that exists in the involved tooth. Unfortunately, the physiodynamics of the inflammatory process do not allow for pain to immediately disappear once the source of the pain is removed. An acute inflammatory process causes increased hydrodynamic pressure in the periodontal ligament space, resulting in a pain response. This inflammatory process may arise from procedures completed during the root canal procedure. These include; hemorrhage resulting from pulpal extirpation, cleaning and shaping of the root canal systems, irrigation, intracanal medications, and/or root canal obturating materials (24).

Injury to the periradicular tissue initiates the inflammatory cascade. Inflammatory mediators; histamine, serotonin, bradykinin, prostaglandin, and leukotriene are released, causing increased vascular permeability and eventually pain $(3,4)$.

Evaluation of analgesic agents to control acute dental pain has been achieved with the use of oral surgery models that involve removal of third molars. Gaston, Mallow, and Frank evaluated the analgesic efficacy of etodolac for 161 patients reporting moderate to severe pain after an oral surgery procedure (surgical removal of multiple teeth or 
extensive multiple extractions with alveoplasty). The patients were given single oral doses of one of the following test drugs: aspirin $650 \mathrm{mg}$; etodolac $50 \mathrm{mg}$; etodolac 200 mg; or a placebo. All active drugs were found to be significantly more effective than a placebo. The $200 \mathrm{mg}$ dose of etodolac provided an earlier onset and longer duration of analgesia than the other test drugs (11).

Fliedner, Levsky, and Kechejian evaluated 380 adult outpatients experiencing postoperative pain following the extraction of one or more third molars. Three studies were conducted with these patients. In two of the studies, four treatment groups were compared: etodolac (100 mg and $200 \mathrm{mg})$; aspirin $(650 \mathrm{mg})$; and a placebo. In the third study, three dose levels of etodolac (50 mg, $100 \mathrm{mg}$, and $200 \mathrm{mg}$ ) were compared with aspirin $(650 \mathrm{mg})$, and a placebo. Etodolac dosages of $100 \mathrm{mg}$ and $200 \mathrm{mg}$ were found to be comparable or superior in analgesic efficacy to $650 \mathrm{mg}$ of aspirin and had a longer duration in all three studies (12).

Winter, et., al., compared the effectiveness of $400 \mathrm{mg}$ and $800 \mathrm{mg}$ of ibuprofen to $650 \mathrm{mg}$ of aspirin, $65 \mathrm{mg}$ of propoxyphene $\mathrm{HCl}$, and a placebo in 510 patients experiencing pain subsequent to oral surgery procedures. Ibuprofen, at both doses, was shown to be more effective for both degree and duration of relief from pain (25).

These studies evaluated the efficacy of pain medications given after treatment was rendered. Other studies have been done to evaluate the effectiveness of preoperative administration of analgesics on post-surgical pain.

In 1978, Dionne and Cooper evaluated the analgesic effects of preoperatively administering $400 \mathrm{mg}$ of ibuprofen on postoperative pain after the surgical removal of 
impacted third molars on 100 patients. They concluded that pretreatment of ibuprofen delayed the mean time of onset of postoperative pain more than 100 minutes, as compared to pretreatment with a placebo. The severity of pain initially experienced postoperatively was less in the group treated preoperatively with ibuprofen (26).

Dionne et., al., continued to study preoperative administration of ibuprofen for removal of impacted third molars in 1983. Subjects were given $800 \mathrm{mg}$ ibuprofen prior to the procedure and $400 \mathrm{mg}$ ibuprofen 4 and 8 hours later. Comparison was made to groups receiving either placebo at all three doses, $600 \mathrm{mg}$ acetaminophen administered on the same schedule, or preoperatively administered placebo followed by two doses of postoperatively administered $600 \mathrm{mg}$ acetaminophen plus $60 \mathrm{mg}$ codeine. Ibuprofen pretreatment resulted in significantly less pain than placebo or acetaminophen pretreatment as the local anesthetic wore off. Ibuprofen also resulted in less postoperative pain than acetaminophen plus codeine following the second dose. The results of these studies suggest that it is possible to delay the onset and lessen the severity of postoperative pain by preoperative administration of a nonsteroidal anti-inflammatory drug, such as ibuprofen (7).

These studies evaluated oral surgery models, while other studies have been completed to evaluate the efficacy of pre-operative medication and their effect on postendodontic pain. Flath concluded that prophylactic administration of flurbiprofen significantly reduced post-endodontic pain in patients who were symptomatic before treatment, compared to patients who received a placebo (27).

Torabinejad et., al., evaluated the effectiveness of nine different medications on 
postoperative pain following complete instrumentation and following root canal obturation. In the first study, three factors (preoperative pain, apprehension, and types of medication) were found to be significant in determining postinstrumentation pain. As the intensity of preoperative pain increased, the chances for more severe postoperative pain increased. An association between the presence of apprehension before any treatment and postoperative pain was also noted. Patients with mild to moderate pain showed no significant difference between the effectiveness of different medications and a placebo in combating postoperative pain. In patients with moderate to severe preoperative pain, ibuprofen, ketoprofen, erythromycin base, penicillin, and methylprednisolone plus penicillin were more effective in controlling postoperative pain than a placebo within the first 48 hours following complete instrumentation (28). In the second study, the incidence of postoperative pain after obturation was lower than that of cleaning and shaping (5.83\% versus $21.76 \%$ ). In addition, no difference was found between the effectiveness of the various medications and a placebo in controlling postoperative pain following obturation (29).

Evaluation of pain and pain relief has been studied using several methods. Seymour studied the use of pain scales in assessing the efficacy of analgesics in postoperative dental pain and found that a $10 \mathrm{~cm}$ visual analog scale was more sensitive than other pain scales and could discriminate between small changes in pain intensity (30). Scoot and Huskisson determined that visual analog and graphic rating scales are the best available method for measuring pain or pain relief (31).

The ultimate goal of analgesic use is pain relief. Nonsteroidal anti-inflammatory 
drugs inhibit prostaglandin synthesis by decreasing the activity of the enzyme cyclooxygenase, which results in decreased formation of prostaglandin precursors.

Researchers have discovered that the cyclo-oxygenase enzyme exists as two separate entities, Cox-1 and Cox-2. Cox-1 synthesizes protective prostaglandins, which preserve the integrity of the stomach lining and maintain normal renal function. Cox-2 is induced by pro-inflammatory cytokines and growth factors, which implies that Cox-2 plays a role in both inflammation and control of cell growth (6). Etodolac, a nonsteroidal antiinflammatory agent, has proven to have a high affinity for the Cox-2 enzyme $(13,14)$. Etodolac has also been proven to be an effective analgesic for rheumatoid arthritis, and in post oral surgery models, but its ability to decrease post-endodontic pain by prophylactic administration has not been investigated (9-12). 


\section{CHAPTER III}

\section{MATERIALS AND METHODS}

\section{SAMPLE DESCRIPTION}

This study involved forty-two patients who required conventional root canal therapy. Each patient was registered and treated at the West Virginia University Dental Clinic and was eighteen years of age or older. A medical history was taken for each patient. A history of one of the following conditions contraindicated the use of the patient for the study; mitral valve prolapse, rheumatic heart disease, artificial heart valves or joints, myocardial infarction, stroke, untreated hypertension, hyperthyroidism, hepatitis, epilepsy, bleeding disorders, stomach ulcers, kidney problems, liver problems, currently pregnant, or current use of medications contraindicated with NSAIDs. Patients were only treated by endodontic residents. The patients were required to pay the West Virginia University Dental School's Resident Fee for the root canal procedure (molar = $\$ 350.00$; premolar $=\$ 300.00 ;$ anterior $=\$ 200.00)$. The patients were not charged for the medication and were reimbursed $\$ 5.00$ for completing and returning the pain survey. 


\section{RESEARCH DESIGN}

This study assessed the ability of prophylactic oral administration of etodolac to reduce post-endodontic pain when compared to ibuprofen, and a placebo. Visual analog scales were used to collect the data over time. The data was analyzed to determine if any difference existed between etodolac, ibuprofen, and a placebo and their ability to reduce post-endodontic pain.

CLINICAL EXAM. Informed consent was obtained and a clinical exam (Appendix C) was administered. The exam included; cold testing (with Endo-Ice), percussion and palpation evaluation, periodontal probing, mobility assessment, and a periapical radiograph. All past and present symptoms of the involved tooth were recorded. A pulpal and periapical diagnosis was determined from the data collected in the exam and was recorded. Data collected in the clinical exam was applied to the flow charts in Appendix E to determine the pulpal and periapical diagnosis.

VISUAL ANALOG SCALE. Prior to administration of the medication, each patient recorded his/her initial perception of pain on the pain survey (Appendix D). Pain intensity was measured using a $100 \mathrm{~mm}$ visual analog scale (VAS). The scale was from zero to one-hundred, zero being "no pain" and one-hundred being "pain so severe you can't stand it". The pain survey included a VAS for; immediately after root canal therapy, 4 hours after, 8 hours after, 12 hours after, 24 hours after, 48 hours after, and 72 hours after root canal therapy was initiated. The pain survey also included an area to 
indicate if additional medication was required after each corresponding time interval.

\section{METHODOLOGY}

Forty-two patients were recruited for this study. All medications are reported to be safe and effective for pain and inflammation by their manufactures. Upon approval by the Institutional Review Board of West Virginia University, (Appendix A), a consent form (Appendix B) was signed by all patients prior to treatment. Patients consented to single blinded oral administration of either $400 \mathrm{mg}$ of etodolac, $600 \mathrm{mg}$ of ibuprofen, or a placebo (Cebocap 3 - Orange), prior to conventional root canal therapy. The three test medications were randomized using a spreadsheet program (Microsoft Excel) into a group of twenty-one. (Appendix F) The randomization sequence was repeated after the first twenty-one participants were evaluated. After oral administration of the test medication, the patient filled out his/her initial perception of pain on the pain survey. Local anesthetic was administered and endodontic access was achieved under rubber dam isolation. Cleaning and shaping of the canal systems was achieved in the following manner; early negotiation and cleaning and shaping was completed with Flex-O-Files \#8, $\# 10$, \#15, \#20, \#25. An initial working length radiograph was taken. The working length was estimated to be $1 \mathrm{~mm}$ short of the radiographic apex. Gates Glidden Burs \#2, \#3, and \#4 were used to enlarge the coronal aspect of the canals. Taper of each canal was achieved with Profile GT rotary files. Profile ISO 0.04 taper files and/or Flex-O-Files were used to create an apical stop at the working length of each canal. Final working 
lengths were confirmed with a radiograph. Irrigation was completed with $5.25 \%$ sodium hypochlorite. RC Prep was used with the Profile GT and the ISO 0.04 rotary files for lubrication.

Cold lateral condensation was used to complete the obturation of each canal. Dia-Dent 0.04 taper gutta percha cones were customized to fit each canal with a gutta percha gauge. The gutta percha cones were measured and introduced into the canal to reconfirm the correct working length. Grossman's sealer was placed into each canal with the master apical file. The master gutta percha cone was dipped in sealer and placed into the canal. Accessory gutta percha points were placed after the use of a D-11 endodontic spreader. Each canal received enough accessory gutta percha points to create a dense three dimensional fill. Thirty-seven of the forty-two cases were completed in one appointment (access, cleaning/shaping and obturation).

A cotton pellet was placed in the pulp chamber space and cavit was used as a temporary filling material. The occlusion was evaluated and reduced when necessary. Final radiographs were taken and the patient was instructed to return to his/her general dentist for a final restoration.

The patient immediately recorded his/her pain perception on the pain survey after completion of the appointment. He/she also recorded his/her pain perception at 4, 8, 12, 24, 48, and 72 hours after root canal therapy was initiated. Postoperative instructions and an extra dosage of the test medication was given to the patient. The patient was instructed to take the extra medication only if needed and record the time it was taken on the pain survey. 


\section{DATA COLLECTION}

The VAS's were measured with a standard millimeter ruler and recorded in the data collection sheet (Table 1). Additional data, was also recorded on the data collection sheet. This included: test medication taken (Med \#), gender, if the patient was taking any medications for conditions other than the involved tooth (Meds), if antibiotics were being taken for the tooth (Anti), pulpal diagnosis (Pulp Dx), periapical diagnosis (Peri Dx), if the canals were obturated (Obtur), if there was an existing restoration (Rest), if additional medication was required after root canal therapy because of post-endodontic pain (XMeds). Table 2 consists of a legend for the data collection sheet.

\section{STATISTICAL ANALYSIS}

Two sets of data were analyzed. The first set compared each medication and the corresponding VAS values for each patient at each time variable. The second set compared the need for extra medication after the completion of root canal therapy with the following: periapical diagnosis, pulpal diagnosis, and if antibiotics were being taken for the tooth,. The first set of data was analyzed using a two-way ANOVA Test. $(\mathrm{P}<0.05)$. The second set of data was analyzed using a Chi-Square Test $(\mathrm{P}<0.05)$.

\section{EQUIPMENT AND MATERIALS}

The following is a list of materials and equipment used in the study: Etodolac (Lodine) - $200 \mathrm{mg}$ capsules (Ayerst Labs, Philadelphia, PA) 
Ibuprofen (Advil) - $200 \mathrm{mg}$ gel caplets (Whitehall-Robins, Madison, NJ)

Placebo (Cebocap 3) - orange capsules (Forest Pharm., St. Louis, MO)

White Gelatin Capsules - Size 1 (Frontier, Norway, IA)

42 individuals requiring conventional root canal therapy

Local Anesthetic (Astra, Westborough, MA)

Flex-O-Files (Dentsply, Milford, DE)

ProFile GT and ISO 0.04 Taper Rotary Files (Tulsa Dental, Tulsa, OK)

Gates-Glidden Burs (Dentsply, Milford, DE)

Standard School of Dentistry Endodontic Set-Up, including Rubber Dam

Cavit (ESPE, Germany)

Roth Root Canal Cement - Type 801 Elite Grade (Roth Inter., Chicago,IL)

5.25\% Sodium Hypochlorite (The Clorox Company, Oakland, CA)

RC Prep (Premier, Norristown, PA)

Endodontic Paper Points (Dentsply, Milford, DE)

Endo-Ice (Hygenic, Akron, OH)

Ektaspeed Plus Dental Film - Size 2 (Kodak, Rochester, NY)

DiaPro 0.04 Taper Gutta Percha Points (DiaDent, Burnaby, B.C., Canada)

Gutta Percha Gauge (Dentsply, Milford, DE)

Accessory Gutta Percha Points (Dentsply, Milford, DE)

Standard Millimeter Ruler

Medical History Form 


\section{CHAPTER IV}

\section{RESULTS AND DISCUSSION}

\section{RESULTS}

Table 1 is a collection of all the data. Forty-two subjects were entered into the study. One subject did not return his pain survey, and five subjects did not have their tooth obturated; therefore, they were dropped from the study and only thirty-six subjects were analyzed. (Subject numbers seventeen, eighteen, twenty-three, twenty-nine, thirty, and thirty-two were not analyzed). Twelve subjects received etodolac, twelve received ibuprofen, and twelve received a placebo prior to root canal therapy. The subjects recorded their perceived pain on a VAS. The values from each VAS were recorded at each time interval. (Initial, Immediately After, 4 Hrs, 8 Hrs, 12 Hrs, 24 Hrs, 48 Hrs, and 72 Hrs after initiation of root canal therapy). Zero equaled, "no pain", and one hundred equaled, "pain so severe you can't stand it". Twenty-two females and fourteen males participated in the study. Nineteen of the thirty-six subjects were taking some type of daily medication that was not for tooth pain. Six of the thirty-six subjects were taking 
antibiotics for their tooth. The antibiotics included Penicillin VK, (three subjects); cephalexin, (two subjects); and clindamycin, (one subject). The pulpal and periapical diagnosis was determined using the diagnosis flow charts and were recorded. Nine patients presented with a normal pulp, eleven presented with an irreversible pulpitis, and sixteen presented with a necrotic pulp. Nine patients presented with a normal periapex, twelve presented with an Acute Apical Periodontitis (AAP), eight presented with a Chronic Apical Periodontitis (CAP), one presented with a Chronic Apical Abscess (CAA), and six presented with a Phoenix Abscess. Twenty-nine of the thirty-six subjects presented with an existing restoration on the involved tooth. Eleven subjects required additional medication to relieve post-endodontic pain.

Figure 1 shows the comparison of each medication and its ability to reduce pain at each time interval. When comparing the ability of ibuprofen to both etodolac and a placebo after four and eight hours from initiation of root canal therapy, ibuprofen is significantly more effective at reducing pain (4 Hours P-value $=0.0111$;

8 Hours P-value $=0.0397)$. Table 3 includes the means and standard deviations for each medication at each time interval.

Table 4 and Figure 2 display the number of subjects who presented with each periapical diagnosis. They also show the number of subjects who required additional medication for post-endodontic pain and their corresponding periapical diagnosis. Nine subjects presented with a normal periapex and zero required additional medication for post-endodontic pain. Twelve subjects presented with AAP and six required additional medication for post-endodontic pain. Eight subjects presented with CAP and one 
required additional medication for post-endodontic pain. One subject presented with CAA and did not require additional medication for post-endodontic pain. Six subjects presented with a Phoenix Abscess and four required additional medication for postendodontic pain. A Chi-square analysis showed that a significant difference existed for the periapical diagnosis and the need for additional medication. $(\mathrm{P}-\mathrm{value}=0.0077)$. Patients who presented with a periapical diagnosis of an Acute Apical Periodontitis or a Phoenix Abscess were more likely to require additional medication for post-endodontic pain than patients who presented with a periapical diagnosis of a Normal Periapex, a Chronic Apical Periodontitis, or a Chronic Apical Abscess.

Table 5 and Figure 3 display the number of subjects who presented with each pulpal diagnosis. They also show the number of subjects who required additional medication for post-endodontic pain and their corresponding pulpal diagnosis. Nine subjects presented with a normal pulp and two subjects required additional medication for post-endodontic pain. Eleven subjects presented with an irreversible pulpitis and three subjects required additional medication for post-endodontic pain. Sixteen subjects presented with a necrotic pulp and six required additional medication for post-endodontic pain. A Chi-square analysis showed that no significant difference existed for the pulpal diagnosis and the need for additional medication. $(\mathrm{P}-\mathrm{value}=0.7524)$.

Table 6 and Figure 4 displays that six subjects were taking antibiotics prior to root canal therapy. Three subjects were taking Penicillin VK, two subjects took cephalexin, and one subject took clindamycin. The amount and duration of use of each antibiotic was unknown for each patient. Of the six subjects taking antibiotics prior to root canal 
therapy, four required additional medication for post-endodontic pain. Thirty subjects were not taking antibiotics prior to root canal therapy, and only seven required additional medication for post-endodontic pain. A Chi-square analysis did not find a significant difference for the use of antibiotics prior to root canal therapy and the need for additional medication, but it was close. $(\mathrm{P}$-value $=0.0517)$. The six subjects who were taking antibiotics prior to root canal therapy had the following periapical diagnoses: AAP $=2$, $\mathrm{CAP}=1$, and Phoenix Abscess $=3$. The four subjects who required additional medication had a periapical diagnosis of the following: $\mathrm{AAP}=1, \mathrm{CAP}=1$, Phoenix Abscess $=2$.

Gender did not play a role in the need for additional medication. 
Table 1.

Data Collection Sheet

\begin{tabular}{|l|c|c|c|c|c|c|c|c|c|c|c|c|c|c|c|c|c|}
\hline Sub \# & Med \# & Initial & Imm After & 4 Hrs & 8 Hrs & 12 Hrs & 24 Hrs & 48 Hrs & 72 Hrs & Gender & Meds & Anti & Pulp Dx & Peri Dx & Obtur & Rest & X-Meds \\
\hline
\end{tabular}

\begin{tabular}{|c|c|c|c|c|c|c|c|c|c|c|c|c|c|c|c|c|c|}
\hline 1 & $\bar{F}$ & $\overline{-5}$ & & & & & & 11 & 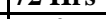 & & $\overline{5}$ & & & & & & \\
\hline$\frac{1}{2}$ & $\frac{0}{2}$ & $\frac{0}{5}$ & $\begin{array}{l}0 \\
\end{array}$ & \begin{tabular}{|l}
11 \\
\end{tabular} & 9 & 3 & 1 & 0 & 0 & 1 & 0 & 0 & \begin{tabular}{|l|}
1 \\
\end{tabular} & \begin{tabular}{|l|} 
\\
\end{tabular} & 1 & 1 & \begin{tabular}{|l}
0 \\
0
\end{tabular} \\
\hline 3 & 1 & 0 & 0 & 5 & 0 & 0 & 0 & 0 & 2 & $\frac{1}{0}$ & $\frac{1}{0}$ & $\frac{1}{0}$ & $\frac{2}{0}$ & 0 & $\frac{1}{1}$ & $\frac{1}{0}$ & 0 \\
\hline 4 & 2 & 0 & 7 & 28 & 31 & 31 & 23 & 22 & 22 & 1 & 1 & 0 & 0 & 0 & 1 & 1 & 0 \\
\hline 5 & 0 & 4 & 2 & 13 & 13 & 49 & 4 & 6 & 8 & 1 & 1 & 0 & 0 & 1 & 1 & 1 & 1 \\
\hline 6 & 1 & 70 & 0 & 0 & 27 & 61 & 13 & 0 & 0 & 1 & 0 & 0 & 1 & 1 & 1 & 1 & 1 \\
\hline 8 & 0 & 46 & 1 & 56 & 45 & 42 & 7 & 4 & 0 & 1 & 1 & 1 & 2 & 5 & 1 & 1 & 1 \\
\hline 9 & 1 & 2 & 0 & 0 & 0 & 0 & 1 & 6 & 0 & 1 & 0 & 0 & 1 & 2 & 1 & 1 & 0 \\
\hline 10 & 0 & 14 & 0 & 0 & 0 & 0 & 0 & 0 & 0 & 0 & 1 & 1 & 2 & 1 & 1 & 1 & 0 \\
\hline 11 & 1 & 0 & 0 & 0 & 4 & 3 & 1 & 0 & 0 & 0 & 0 & $\frac{1}{0}$ & $\frac{2}{0}$ & 0 & 1 & $\frac{1}{1}$ & 0 \\
\hline 14 & 2 & 0 & 5 & 14 & 47 & 58 & 89 & 96 & 99 & 1 & 0 & 0 & 2 & 5 & 1 & 1 & 1 \\
\hline 15 & 2 & 63 & 32 & 22 & 24 & 3 & 4 & 2 & 1 & 0 & 1 & 1 & 2 & 5 & 1 & 1 & 1 \\
\hline 16 & 2 & 0 & 0 & 0 & 0 & 0 & 0 & 0 & 0 & 1 & 1 & 0 & 0 & 0 & 1 & 1 & 0 \\
\hline 17 & 0 & 0 & 0 & 76 & 0 & 0 & 0 & 0 & 0 & 1 & 0 & 0 & 0 & 0 & 0 & 0 & 1 \\
\hline 18 & 2 & 0 & 0 & 0 & 0 & 0 & 0 & 0 & 0 & 0 & 1 & 0 & 0 & 0 & 0 & 0 & 0 \\
\hline 19 & 1 & 0 & 0 & 0 & 0 & 0 & 0 & 0 & 0 & 0 & 1 & 0 & 2 & 2 & 1 & 1 & 0 \\
\hline 20 & 1 & 99 & 0 & 26 & 17 & 66 & 43 & 28 & 16 & 1 & 1 & 0 & 1 & 1 & 1 & 0 & 1 \\
\hline 21 & 1 & 13 & 23 & 9 & 5 & 3 & 50 & 39 & 13 & 1 & 1 & 0 & 1 & 1 & 1 & 1 & 1 \\
\hline 28 & 2 & 3 & 4 & 3 & 3 & 4 & 0 & 0 & 0 & 1 & 1 & 0 & 1 & 1 & 1 & 1 & 0 \\
\hline 29 & 0 & & & & & & & & & 0 & & & & & & & \\
\hline 30 & 1 & 3 & 0 & 9 & 6 & 3 & 3 & 1 & 0 & 1 & 0 & 0 & 1 & 0 & 0 & 1 & 0 \\
\hline 31 & 0 & 0 & 0 & 6 & 6 & 7 & 9 & 0 & 0 & 1 & 1 & 1 & 2 & 1 & 1 & 1 & 1 \\
\hline 32 & 1 & 2 & 2 & 6 & 2 & 1 & 0 & 0 & 0 & 0 & 0 & 0 & 2 & 2 & 0 & 1 & 0 \\
\hline 33 & 0 & 3 & 4 & 2 & 2 & 2 & 2 & 3 & 3 & 1 & 0 & 0 & 1 & 1 & 1 & 1 & 0 \\
\hline 34 & 0 & 85 & 10 & 29 & 32 & 17 & 5 & 5 & 5 & 0 & 0 & 0 & 2 & 5 & 1 & 0 & 1 \\
\hline 35 & 2 & 0 & 0 & 0 & 0 & 0 & 0 & 0 & 0 & 1 & 0 & 0 & 2 & 5 & 1 & 1 & 0 \\
\hline 36 & 2 & 0 & 0 & 0 & 0 & 0 & 0 & 0 & 0 & 1 & 1 & 0 & 1 & 0 & 1 & 1 & 0 \\
\hline 37 & 2 & 37 & 0 & 0 & 0 & 0 & 0 & 0 & 0 & 0 & 0 & 0 & 1 & 0 & 1 & 1 & 0 \\
\hline 38 & 0 & 0 & 0 & 5 & 6 & 2 & 1 & 1 & 1 & 0 & 0 & 0 & 0 & 0 & 1 & 1 & 0 \\
\hline 39 & 2 & 4 & 0 & 6 & 5 & 2 & 0 & 0 & 0 & 0 & 1 & 0 & 1 & 1 & 1 & 1 & 0 \\
\hline 40 & 1 & 10 & 1 & 0 & 1 & 1 & 1 & 0 & 0 & 0 & 1 & 0 & 2 & 4 & 1 & 1 & 0 \\
\hline 41 & 1 & 5 & 0 & 3 & 4 & 4 & 3 & 1 & 2 & 0 & 1 & 0 & 0 & 1 & 1 & 0 & 0 \\
\hline 42 & 1 & 0 & 0 & 0 & 0 & 0 & 0 & 0 & 0 & 1 & 1 & 0 & 2 & 2 & 1 & 1 & 0 \\
\hline
\end{tabular}


Table 2.

Data Collection Sheet Legend

\begin{tabular}{|c|c|c|c|l|l|l|}
\hline Med \# & $0=$ Placebo & $1=$ Ibuprofen & 2 Etodolac & & & \\
\hline Gender & $0=$ Male & $1=$ Female & & & & \\
\hline Meds & $0=$ No & $1=$ Yes & & & & \\
\hline Anti & $0=$ No & $1=$ Yes & & & & \\
\hline Pulp Dx & $0=$ Normal & $1=$ Irreversible Pulpitis & $2=$ Necrotic Pulp & & & \\
\hline Peri Dx & $0=$ Normal & $1=$ AAP & $2=$ CAP & $3=$ AAA & $4=$ CAA & $5=$ Phoenix Abscess \\
\hline Obtur & $0=$ No & $1=$ Yes & & & & \\
\hline Rest & $0=$ No & $1=$ Yes & & & & \\
\hline X-Meds & $0=$ No & $1=$ Yes & & & & \\
\hline
\end{tabular}

All subjects and corresponding data that are shaded gray in Table 1 were not analyzed 


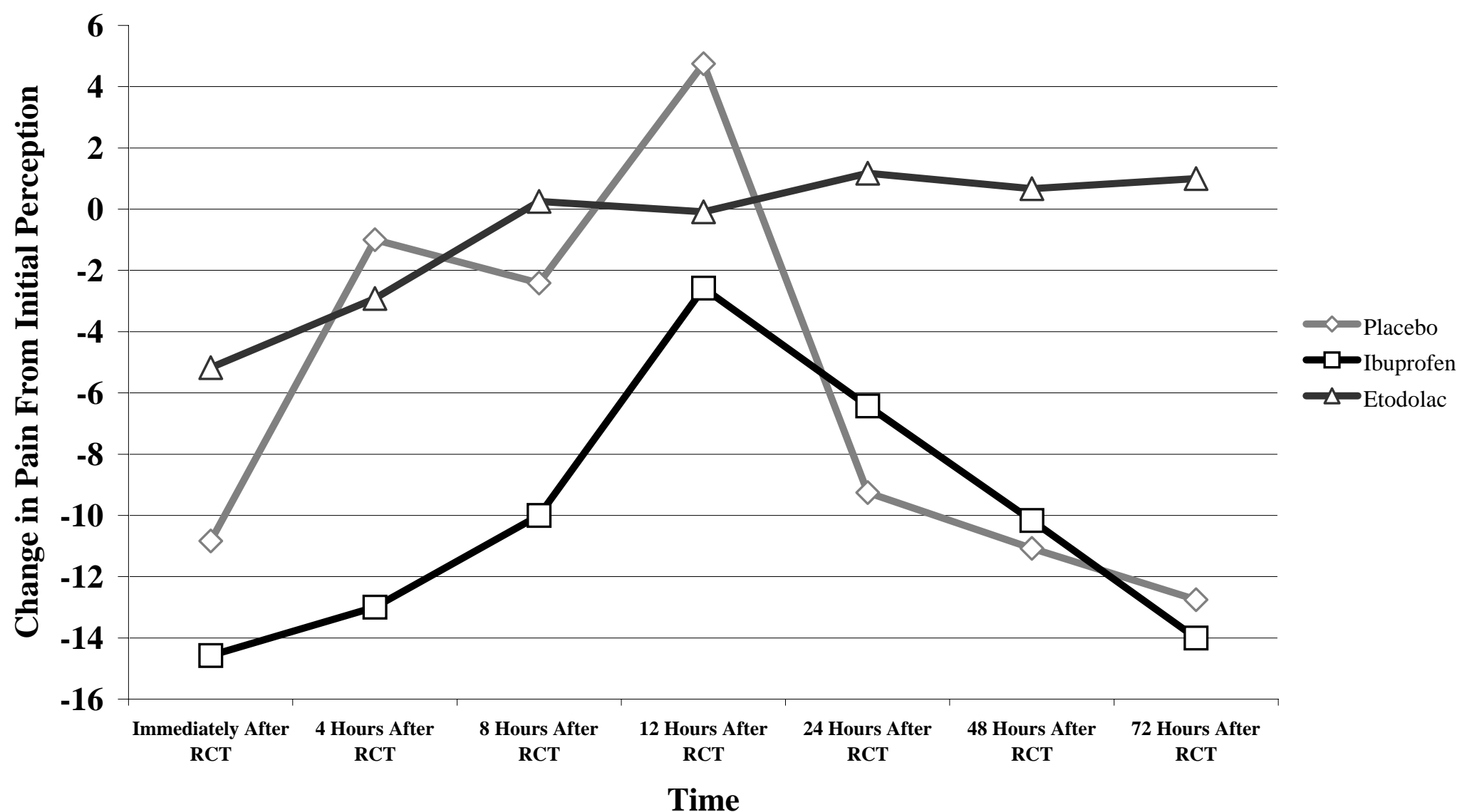

* = significant difference exists for $\mathrm{P}<0.04$

Figure 1.

Experimental Medications and Pain Relief Over Time 
Table 3.

$\underline{\text { Means and Standard Deviations }}$

\begin{tabular}{|c|c|c|c|}
\hline Medication & Time & Mean & Standard Deviation \\
\hline \hline Placebo & Immediately After RCT & -10.83 & 24.42 \\
\hline Placebo & 4 Hours After RCT & -1 & 19.18 \\
\hline Placebo & 8 Hours After RCT & -2.42 & 17.3 \\
\hline Placebo & 12 Hours After RCT & 4.75 & 38.07 \\
\hline Placebo & 24 Hours After RCT & -9.25 & 26.89 \\
\hline Placebo & 48 Hours After RCT & -11.08 & 26.1 \\
\hline Placebo & 72 Hours After RCT & -12.75 & 25.26 \\
\hline \hline Ibuprofen & Immediately After RCT & -14.58 & 33.52 \\
\hline Ibuprofen & 4 Hours After RCT & -13 & 27.55 \\
\hline Ibuprofen & 8 Hours After RCT & -10 & 26.93 \\
\hline Ibuprofen & 12 Hours After RCT & -2.58 & 14.1 \\
\hline Ibuprofen & 24 Hours After RCT & -6.42 & 25.96 \\
\hline Ibuprofen & 48 Hours After RCT & -10.17 & 29.42 \\
\hline Ibuprofen & 72 Hours After RCT & -14 & 29.46 \\
\hline \hline Etodolac & Immediately After RCT & -5.17 & 13.87 \\
\hline Etodolac & 4 Hours After RCT & -2.92 & 18.97 \\
\hline Etodolac & 8 Hours After RCT & 0.25 & 23.48 \\
\hline Etodolac & 12 Hours After RCT & -0.08 & 29.12 \\
\hline Etodolac & 24 Hours After RCT & 1.17 & 34.81 \\
\hline Etodolac & 48 Hours After RCT & 0.67 & 36.72 \\
\hline Etodolac & 72 Hours After RCT & 1 & 37.56 \\
\hline
\end{tabular}

* The mean equals the change in pain from the initial perception of pain. 
Table 4.

$\underline{\text { Periapical Diagnosis and Additional Medication }}$

\begin{tabular}{|c|c|c|}
\hline Periapical Dx & Subjects & Subjects Requiring Extra Meds \\
\hline Normal & 9 & 0 \\
\hline AAP & 12 & 6 \\
\hline CAP & 8 & 1 \\
\hline CAA & 1 & 0 \\
\hline Phoenix Abscess & 6 & 4 \\
\hline
\end{tabular}




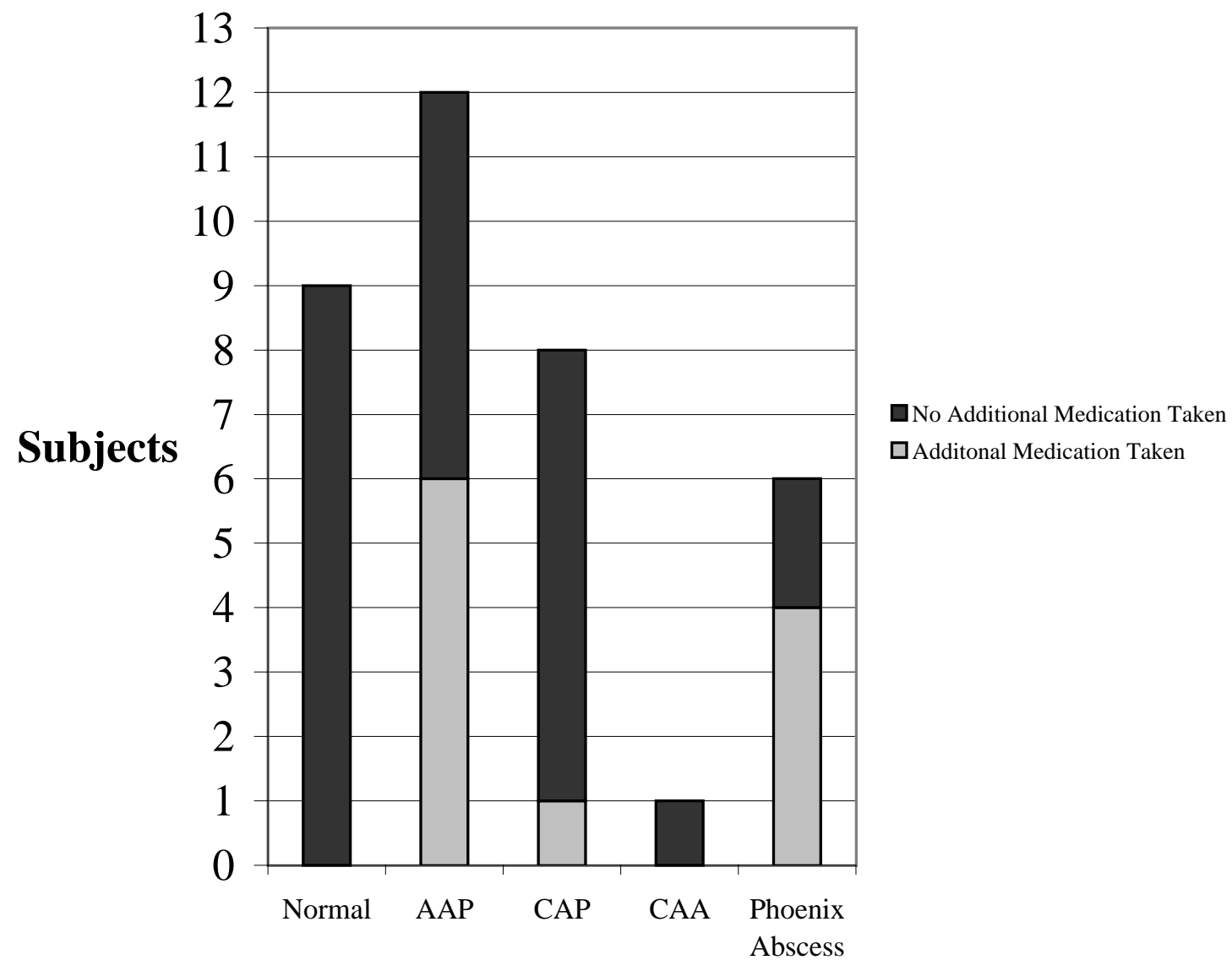

Periapical Diagnosis

Figure 2.

Periapical Diagnosis and Additional Medication 
Table 5.

$\underline{\text { Pulpal Diagnosis and Additional Medication }}$

\begin{tabular}{|c|c|c|}
\hline Pulpal Dx & Subjects & Subjects Requiring Extra Meds \\
\hline Normal & 9 & 2 \\
\hline Irreversible Pulpitis & 11 & 3 \\
\hline Necrotic Pulp & 16 & 6 \\
\hline
\end{tabular}




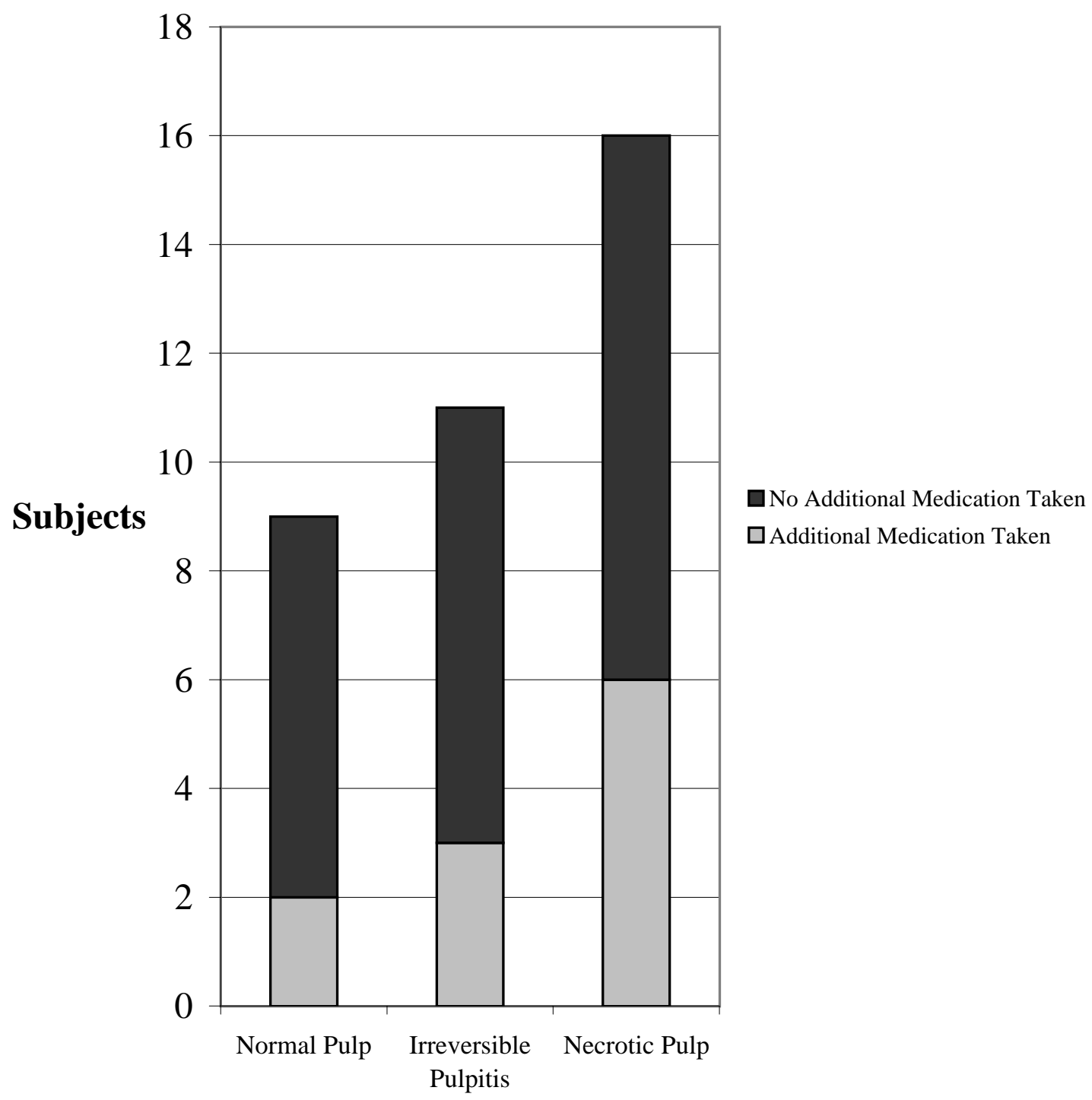

\section{Pulpal Diagnosis}

Figure 3.

Pulpal Diagnosis and Additional Medication 
Table 6.

$\underline{\text { Antibiotics Taken for Tooth and Additional Medication }}$

\begin{tabular}{|c|c|c|}
\hline Antibiotics Taken for Tooth & Subjects & Subjects Requiring Extra Meds \\
\hline Yes & 6 & 4 \\
\hline No & 30 & 7 \\
\hline
\end{tabular}




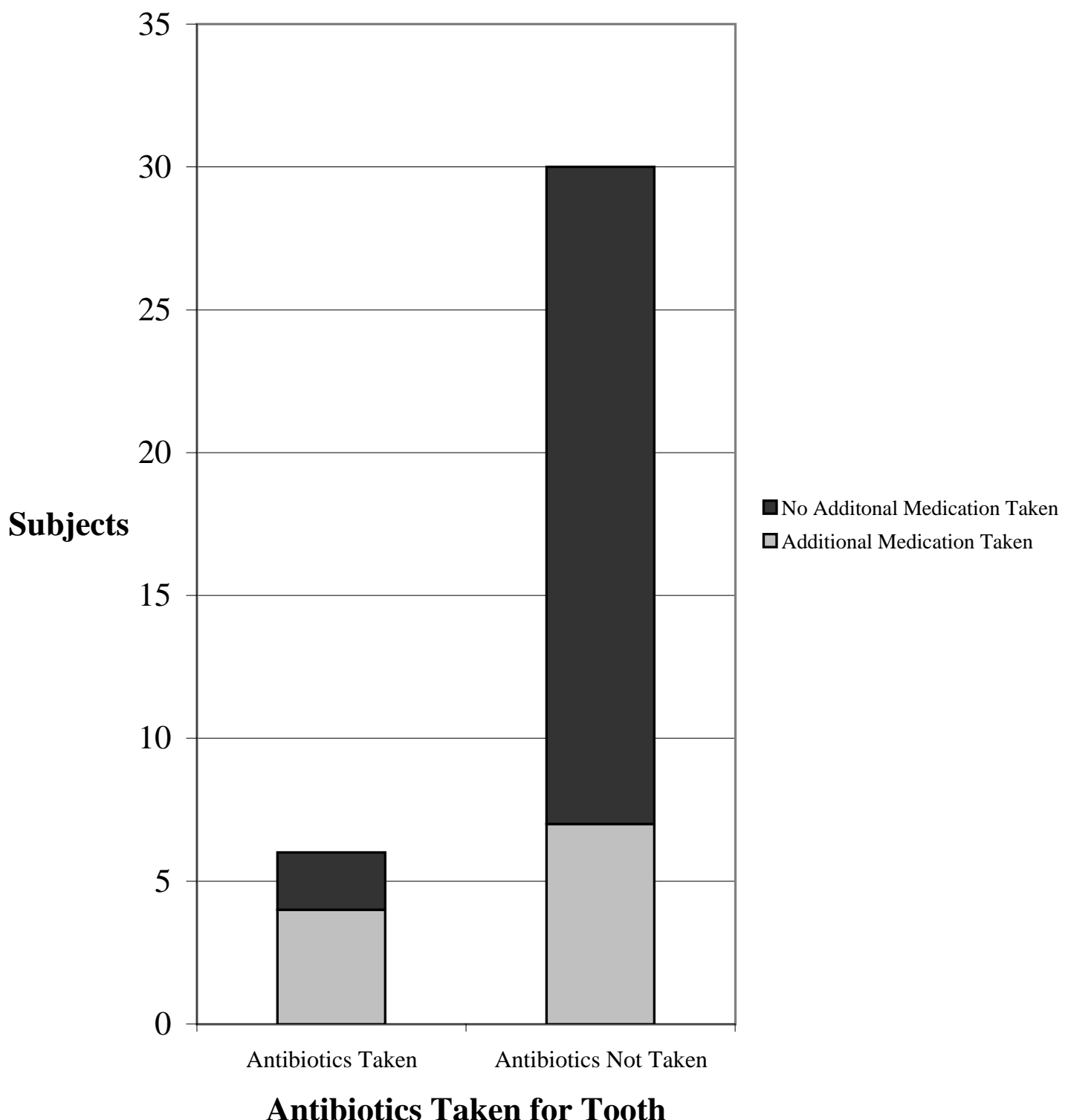

Figure 4.

Antibiotics Taken for Tooth and Additional Medication 


\section{DISCUSSION}

Prophylactic oral administration of a non-steroidal anti-inflammatory drug has been proven to reduce postoperative pain in oral surgery models and in root canal therapy models $(7,8,11,12,25,26)$. By administering NSAIDs prior to root canal therapy, the cyclo-oxygenase pathway can be blocked and the pain sensation can be prevented before it even begins. Ibuprofen was significantly better at reducing pain after four and eight hours from initiation of root canal therapy compared to etodolac and a placebo.

From the diagnosis flow charts a Phoenix Abscess and an Acute Apical Periodontitis both have the characteristic of pain to percussion. As stated by O'Keefe, a significant relationship exists between preoperative and postoperative endodontic pain. Patients with severe preoperative pain tend to have more severe operative and postoperative pain than patients with mild or no preoperative pain (2). Torabinejad found as the intensity of preoperative pain increased, the chances for more severe postoperative pain increased $(28,29)$. Eighteen patients presented with pain to percussion and ten of them required additional medication to reduce post-endodontic pain. This study indicated that if a patient originally presents with pain to percussion, it is likely that he/she will need additional medication to relieve post-endodontic pain.

The characteristics of a Chronic Apical Periodontitis include a radiolucency at the root apex and no pain to percussion. A Chronic Apical Abscess consists of a radiolucency at the root apex, a draining fistula (sinus tract), and usually no pain to percussion. A patient presenting with a periapical diagnosis of a CAP, CAA, or a normal periapex is not experiencing pain before root canal therapy; therefore, he/she is less likely 
to experience post-endodontic pain. In this study, eighteen patients presented with a normal periapex, CAP, or CAA, and only one required additional medication for postendodontic pain.

This study found that a significant difference did not exist for the pulpal diagnosis and the need for additional medication after completion of root canal therapy. It can be argued that after the pulp (the source of the infection) is removed, the inflammatory cascade is halted and additional medication may not be required for postoperative pain.

Six patients were taking antibiotics for their tooth prior to root canal therapy. Four of those six required additional medication for post-endodontic pain. Antibiotics function to provide time for the normal host defenses to gain control and eventually eliminate the infectious process. A patient taking antibiotics usually presents with swelling and/or pain. If the patient presents for root canal therapy in pain, he/she is more likely to experience post-endodontic pain. In this study six patients presented for root canal therapy taking antibiotics and four required additional medication for postendodontic pain.

Periapical diagnoses of an AAP and a Phoenix Abscess both are painful to percussion. After performing root canal therapy on a tooth that is painful to percussion, it seems logical to reduce the occlusion. A recent study by Rosenberg, et., al., found that occlusal reduction should prevent postoperative pain in those patients whose teeth initially exhibit pulp vitality, percussion sensitivity, preoperative pain, and/or the absence of a periradicular radiolucency (32). From Rosenberg's study and this study's findings, perhaps all teeth presenting with a periapical diagnosis of an AAP or a Phoenix Abscess 
should have the occlusion completely reduced after root canal therapy.

In 1991, researchers discovered that the cyclo-oxygenase enzyme exists as two separate entities; Cox-1 and Cox-2. Cox-1 synthesizes protective protaglandins, which preserve the integrity of the stomach lining. Cox-2 is mostly responsible for producing prostaglandins for pain and inflammation (6).

Etodolac has been proven to have a high affinity to block the Cox-2 enzyme $(13,14)$. It seems logical to administer a drug that will selectively block prostaglandins that produce pain and inflammation, while not interrupting production of prostaglandins that protect the stomach lining. This study found that administering $600 \mathrm{mg}$ of ibuprofen prior to root canal therapy was more effective at reducing post-endodontic pain at four and eight hours after initiation of treatment, when compared to $400 \mathrm{mg}$ of etodolac and a placebo.

Ibuprofen blocks both the Cox-1 and Cox-2 enzymes but it is a safe, inexpensive, and effective analgesic and anti-inflammatory for post-endodontic pain. Etodolac blocks the Cox-2 enzyme but was not as effective for post-endodontic pain as ibuprofen. Perhaps etodolac does not have a high affinity for the inflammatory components of an endodontic infection or perhaps there is an unknown inflammatory component that ibuprofen has a high affinity for that etodolac will not block. 


\section{CHAPTER V}

\section{SUMMARY AND CONCLUSIONS}

\section{SUMMARY}

Root canal therapy induces post-endodontic pain $(2,16-24)$. The purpose of this study was to determine if prophylactic oral administration of etodolac would significantly decrease post-endodontic pain when compared to ibuprofen, and when compared to a placebo.

It was hypothesized that etodolac would provide significantly better pain relief when compared to ibuprofen and a placebo. It was also hypothesized that the pulpal or periapical diagnosis of the tooth would not affect the ability of the medication to decrease post-endodontic pain.

Forty-two subjects were given oral prophylactic administration of either $400 \mathrm{mg}$ of etodolac, $600 \mathrm{mg}$ of ibuprofen, or a placebo prior to root canal therapy. One subject did not return his pain survey. Five subjects did not have their root canals obturated; therefore, thirty-six subjects were analyzed. (Twelve for each medication) 
A significant difference was found for the ability of ibuprofen to reduce postendodontic pain after four and eight hours after initiation treatment, when compared to etodolac and a placebo. A significant difference was also found for the periapical diagnosis and the need for additional medication after root canal therapy was completed. A periapical diagnosis of an Acute Apical Periodontitis or a Phoenix Abscess, significantly required the need for additional medication compared to a periapical diagnosis of a Normal Periapex, Chronic Apical Periodontitis, or a Chronic Apical Abscess. A significant difference did not exist for the pulpal diagnosis and the need for additional medication. A significant difference did not exist if the patient was taking antibiotics for the involved tooth and the need for additional medication for postendodontic pain.

This study found when performing conventional root canal therapy, if the patient presents with a periapical diagnosis of an Acute Apical Periodontitis or a Phoenix Abscess he/she is more likely to require additional pain medications to relieve postendodontic pain compared to a periapical diagnosis of a Normal Periapex, a Chronic Apical Periodontitis, or a Chronic Apical Abscess. Rosenberg found that occlusal reduction should prevent postoperative pain in patients who exhibit pulp vitality, percussion sensitivity, preoperative pain, and/or absence of a radiolucency (32). From Rosenberg's study and this study's findings, perhaps all teeth presenting with a periapical diagnosis of an AAP or a Phoenix Abscess should have the occlusion completely reduced after root canal therapy to eliminate post-endodontic pain. 


\section{CONCLUSIONS}

Two conclusions can be drawn from this study:

1. Prophylactic ibuprofen will significantly reduce post-endodontic pain at four and eight hours after initiation of treatment, when compared to etodolac and a placebo.

2. A patient presenting for root canal therapy, with a periapical diagnosis of an Acute Apical Periodontitis or a Phoenix Abscess, is more likely to require additional medication to relieve post-endodontic pain compared to a periapical diagnosis of a Normal Periapex, a Chronic Apical Periodontitis, or a Chronic Apical Abscess. 


\section{REFERENCES}

1. Morse DR, Furst ML. Stress and the oral cavity. In: Selye H, ed. Seyle's guide to stress research. Vol. 2. New York: Van Nostrand Reinhold Co., 1983:244-5.

2. O'Keefe EM, Pain in endodontic therapy: preliminary study. J. Endodon 1976; 2:315-319.

3. Weissman G. Prostaglandins in acute inflammation. Current concept. Kalamazoo, MI: The Upjohn Co., 1980:5-13.

4. Ryan GB, Majno G. Inflammation. Kalamazoo, MI: Scope Publications, The Upjohn Co., 1977:51-2.

5. Kuehl FA, Egan RW. Prostaglandins, arachidonic acid, and inflammation. Science $1980 ; 210: 978-84$.

6. Vane JR, Bakhle YS, Botting RM. Cyclooxygenases 1 and 2. Annu Rev Pharmacol Toxicol 1998; 38:97-120.

7. Dionne RA, Campbell RA, Cooper SA, Hall DL, Buckingham B. Suppression of postoperative pain by the preoperative administration of ibuprofen in comparison to placebo, acetaminophen, and acetaminophen plus codeine. J Clin Pharmacol $1983 ; 23: 37-43$.

8. Dionne RA, Sisk AL, Fox PC, Wirkzek PR, Gracely RH, Dubner R. Suppression of 
postoperative pain by preoperative administration of flurbiprofen in comparison to acetaminophen and oxycodone plus acetaminophen. Curr Ther Res 1983; 34:15-29.

9. Neustadt DH. Double blind evaluation of the longterm effects of etodolac versus ibuprofen in patients with rheumatoid arthritis. J Rheumatology 1997; 24 S47:17-22.

10. Spencer-Green G. Low dose etodolac in rheumatoid arthritis: a review of early studies. J Rheumatology 1997; 24 S47:3-9.

11. Gaston GW, Mallow RD, Frank JE. The efficacy of etodolac for patients with pain following oral surgery. J Oral Maxillofac Surg 1984; 42:362-366.

12. Fliedner L, Levsky M, Kechejian H, Berger J, Gaston G, Hutton CE. Analgesia with etodolac in oral postsurgical pain. Current Therapeutic Research 1984; 36:33-45.

13. Laine L, Sloane R, Ferretti M, Cominelli F. A randomized double-blind comparison of placebo, etodolac, and naproxen on gastrointestinal injury and prostaglandin production. Gastrointest Endosc 1995; 42:428-433.

14. Dvornik DM. Tissue selective inhibition of prostaglandin biosynthesis by etodolac. J Rheumatol 1997; 47:40-47.

15. AAE Endodontics Colleagues for Excellence. Management of acute pain. 1995; Spring/Summer:1-4.

16. Seltzer S, Bender IB, Ehrenreich J. Incidence and duration of pain following endodontic therapy. OOO 1961; 14:74-82. 
17. Fox J, Atkinson JS, Dinin AP, Greenfield E, Hechtman E, Reeman CA, Salkind M, Todaro CJ. Incidence of pain following one-visit endodontic treatment. OOO 1970; 30:123-130.

18. Genet JM, Hart AAM, Wesselink PR, Thoden VanVelzen SK. Preoperative and operative factors associated with pain after the first endodontic visit. International Endodontic Journal 1987; 20:53-64.

19. Harrison JW, Baumgartner JC, Svec TA. Incidence of pain associated with clinical factors during and after root canal therapy. Part 1. Interappointment Pain. J Endodon 1983; 9:384-387.

20. Harrison JW, Baumgartner JC, Svec TA. Incidence of pain associated with clinical factors during and after root canal therapy. Part 2. Postobturation Pain. J Endodon 1983; 9:434-438.

21. Pisano JV, Foley DB, Sonnenberg BC, Weine FS. A survey of postoperative pain associated with endodontic therapy. Compendium of Continuing Education in Dentistry $1985 ; 6: 533-537$.

22. Morse DR. One-visit endodontics. Hawaii Dent J 1987; 18:12.

23. Mulhern JM, Patterson SS, Newton CW, Ringel AM. Incidence of postoperative pain after one-appointment endodontic treatment of asympotomatic pulpal necrosis in single-rooted teeth. J Endodon 1982; 8:370-375. 
24. Glassman GD, Serota KS. Sequelae of endodontic therapy; the biologic rationale for postoperative pain. Oral Health. 1994; 84:17-23.

25. Winter L, Bass E, Recant B, Cahaly JF. Analgesic activity of ibuprofen (motrin) in postoperative oral surgical pain. OOO 1978; 45:159-166.

26. Dionne RA, Cooper SA. Evaluation of preoperative ibuprofen for postoperative pain after removal of third molars. OOO 1978; 45:851-6.

27. Flath RK, Hicks ML, Dionne RA, Pelleu GB. Pain Suppression after pulpectomy with preoperative flurbiprofen. J Endodon 1987; 13:339-347.

28. Torabinejad M, Cymerman JJ, Frankson M, Lemon RR, Maggio JD, Schilder H. Effectiveness of various medications on postoperative pain following complete instrumentation. J Endodon 1994; 20:345-354.

29. Torabinejad M, Dorn SO, Eleazer PD, Frankson M, Jouhari B, Mullin RK, Soluti A. Effectiveness of various medications on postoperative pain following root canal obturation. J Endodon 1994; 20:427-431.

30. Seymour RA. The use of pain scales in assessing the efficacy of analgesics in postoperative dental pain. Eur J Clin Pharmacol 1982; 23:441-444.

31. Scott J, Huskisson EC. Graphic representation of pain. Pain 1976; 2:175-184.

32. Rosenberg PA, Babick PJ, Schertzer L, Leung A. The effect of occlusal reduction on pain after endodontic instrumentation. J Endodon 1998; 24:492-496. 


\section{APPENDIX A}

Institutional Review Board Approval Form 
DATE: July 1, 1998

NOTICE OF APPROVAL FOR PROTOCOL H.S. \#14146 Addm. \#2

(Changing back to original drug and title)

This research will be monitored for re-approval annually. This protocol was first approved on May 14, 1998.

TO: Eric Menke

Project Title: The Effectiveness of Prophylactic Etodolac on Post Endodontic Pain

\section{SPONSORING AGENCY: N/A}

The Institutional Review Board for the Protection of Human Research Subjects (IRB) has approved the project described above. Approval was based on the descriptive material and procedures you submitted for review. Should any changes in your protocol/consent form be necessary, prior approval must be obtained from the IRB.

According to the Code of Federal Regulations, Section 312.32, investigators are required to notify the FDA and the study sponsor of any adverse experience associated with the use of an investigational drug that is serious and unexpected. A serious adverse experience is considered any event that is fatal or life-threatening, is permanently disabling, requires inpatient hospitalization, or is a congenital anomaly, cancer, or overdose. An unexpected adverse experience is an event that is not identified in nature, severity, or frequency in the current investigator brochure. Any experience reportable to FDA and the sponsor must also be reported immediately to the IRB.

A consent form* $\mathrm{X}$ is - is not required of each subject.

An assent form_ is $X_{-}$is not required of each subject.

A recruitment ad has __ has not $\mathrm{X}$ been approved. 
Page 2-

Menke

HS \#14146

July 1, 1998

* Only copies of the consent and/or assent form with the IRB's approval stamp may be used with human subject research. It is the responsibility of the investigator to submit a revised consent form for the IRB's approval should funding be obtained. This stamped consent form must then be used for subjects enrolled. A copy of each subject's signed Consent/Assent Form must be retained by the investigator and accessible to federal regulatory authorities for at least three years after the study is completed.

\footnotetext{
Marian 8 . Turner

IRB/ACUC Administrator
}

MJT/baw 
APPENDIX B

Consent Form 


\section{THE EFFECTIVENESS OF PROPHYLACTIC ETODOL
ON POST-ENDODONTIC PAIN}

WEST VIRGINUA UNIVERSITY

Cisttution Review Bowerd for the

\section{CONSENT FORM}

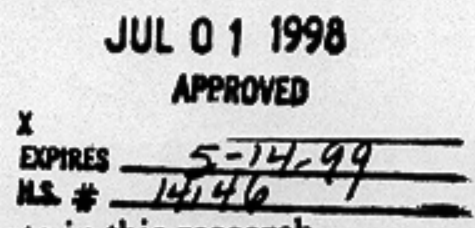

INTRODUCTION: I, have been invited to participate in this research study in the Department of Endodontics, which has been explained to me by This research is being conducted by Eric $R$. Menke to fulfill the requirements of a masters thesis in Endodontics at West Virginia University.

PURPOSE OF STUDY: The purpose of this study is to learn more about the effectiveness of etodolac on pain following a root canal procedure.

DESCRIPTION OF PROCEDURES: I have agreed to a root canal procedure. This study involves oral administration of either etodolac, ibuprofen, or a placebo before a root canal procedure. I will record my initial pain perception on a pain survey form. I may see the pain survey form before signing this consent. It will take approximately one minute to complete. I understand that I do not have to answer every question. My dentist will numb my tooth and then begin to work on it. The entire procedure will take approximately $60-90$ minutes.

Approximately 75 subjects will be entered in the study. I will be required to fill out the pain survey form at; immediately after root canal therapy, 4 hours, 8 hours, 12 hours, 24 hours. 48 hours, and 72 hours after the root canal procedure is started. I will return the questionnaire at my next visit or I will be able to return it via the mail.

BENEFITS: I understand that this study is not expected to be of direct benefit to me, but the knowledge gained may be of benefit to others. I will receive either etodolac, ibuprofen, or a placebo at no additional charge.

RISKS AND DISCOMFORTS: There are no known or expected risks from participating in this study other than the normal possible side effects of NSAIDs, which include; stomach ache, rashes, nausea, vomiting, and/or diarrhea. An allergic reaction may develop, which may include a rash. Lack of pain relief may occur from the medication.

FINANCIAL CONSIDERATIONS: I will be required to pay for the root canal procedure but will not be charged for the medication.

VOLUNTARY COMPENSATION: If injury occurs, medical treatment will be available; however, voluntary compensation will not be provided by Eric R. Menke, West Virginia University, or its associated affiliates. 
ALTERNATIVES: If I do not participate in the study, the same drugs can be used to eliminate pain. Not to participate in the study is an alternative. Other medications that are standard for pain relief include; aspirin and acetaminophen.

CONTACT PERSON: For more information about this research, I can contact Eric R. Menke, at 304-293-0627. For more information regarding my rights as a research subject, I may contact the Executive Secretary of the Institutional Review Board at 304-293-7073. If additional pain medication is needed, I can contact Eric R. Menke at 304-293-0627.

CONFIDENTIALITY: I understand that any information about me obtained as a result of my participation in this research will be kept as confidential as legally possible. I understand that my research records, just like hospital records, may be subpoenaed by court order or may be inspected by the sponsor or federal regulatory authorities, including the Food and Drug Administration, without my additional consent. In any publications that result from this research, neither my name or any information from which I might be identified will be published without my consent.

VOLUNTARY PARTICIPATION: Participation in this study is voluntary. I understand that I am free to withdraw my consent to participate in this study at any time. Refusal to participate or withdraw will involve no penalty or loss of the benefits. I have been given the opportunity to ask questions about the research, and I have received answers concerning areas I did not understand.

Upon signing this form, I will receive a copy.

I willingly consent to participate in this study.

Signature of Subject

Date

Signature of Investigator

Date 


\section{APPENDIX C}

\section{Clinical Exam Form}


Name: Phone \# Patient \# Tooth \#

\section{Patient History}

Age:

Gender:

Male Female

Allergies? Yes No If yes, what to?

Is the patient currently taking any medications?

If yes, what type and what for?

\section{Clinical Exam}

Cold Sensitive:
Hot Sensitive:
Spontaneous Pain:
Percussion Sensitive:
Sinus Tract:
Mobility:
Perio Pocket Depths:
Existing Restoration:
If yes, what kind?
Is the pulp chamber exposed?
Occlusion:

Diagnosis

Pulpal

Normal (RCT for Prosth)
Irreversible Pulpitis
Necrotic Pulp

Yes No

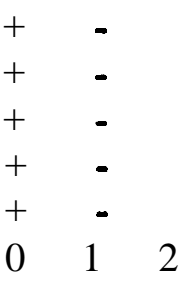

WNL Deep pocket at _ _ $\quad \mathrm{mm}$ Yes No

Yes No

Normal Hyper None

\section{Periapical} Normal

Acute Apical Periodontitis

-- Chronic Apical Periodontitis Acute Apical Abscess Chronic Apical Abscess Phoenix Abscess

\section{Treatment}

Anesthetic Type:

Amount: cc

Germicide:

Level of Instrumentation:

Pulp Chamber:

Ideal Short Long

Dry chamber Blood Pus

\begin{tabular}{|c|c|c|c|c|}
\hline Canal & Size & Lenoth & $\mathrm{mm} \quad \mathrm{GG}$ & Profile \\
\hline Canal_ & Size & Length & $\mathrm{mm} \quad \mathrm{GG}$ & Profile \\
\hline Canal & Size & Length & $\mathrm{mm} \quad \mathrm{GG}$ & Profile \\
\hline Cana & Size & Length & $\mathrm{m} \mathrm{m} \quad \mathrm{GG}$ & Profile \\
\hline
\end{tabular}

Obterated?

Yes No

Filling Cement:

Filling Technic:

Filling Material:

Fill Evaluation: $1 \mathrm{~mm}$ from apex $\quad$ Past Apex Shorter than $1 \mathrm{~mm}$ from apex 
APPENDIX D

\section{Pain Survey}


Patient \# Tooth \#

Date Time Started

Initial

None

Pain so severe

Evaluation you can't stand it

I mmediately None Pain so severe After R CT you can't stand it

4 H rs After None Pain so severe you can't stand it

Was additional pain medication required? Yes No At what time?

8 Hrs After None Pain so severe you can't stand it

Was additional pain medication required? Yes No At what time?

12 Hrs After N one Pain so severe you can't stand it

Was additional pain medication required? Yes No At what time?

24 H rs After None

Pain so severe you can't stand it

Was additional pain medication required? Yes No At what time?

48 Hrs After None Pain so severe you can't stand it

Was additional pain medication required? Yes No At what time?

72 H rs After None Pain so severe you can't stand it

Was additional pain medication required? Yes No At what time? 


\section{APPENDIX E}

Pulpal and Periapical Diagnosis Flow Charts 


\section{Pulpal Diagnosis}

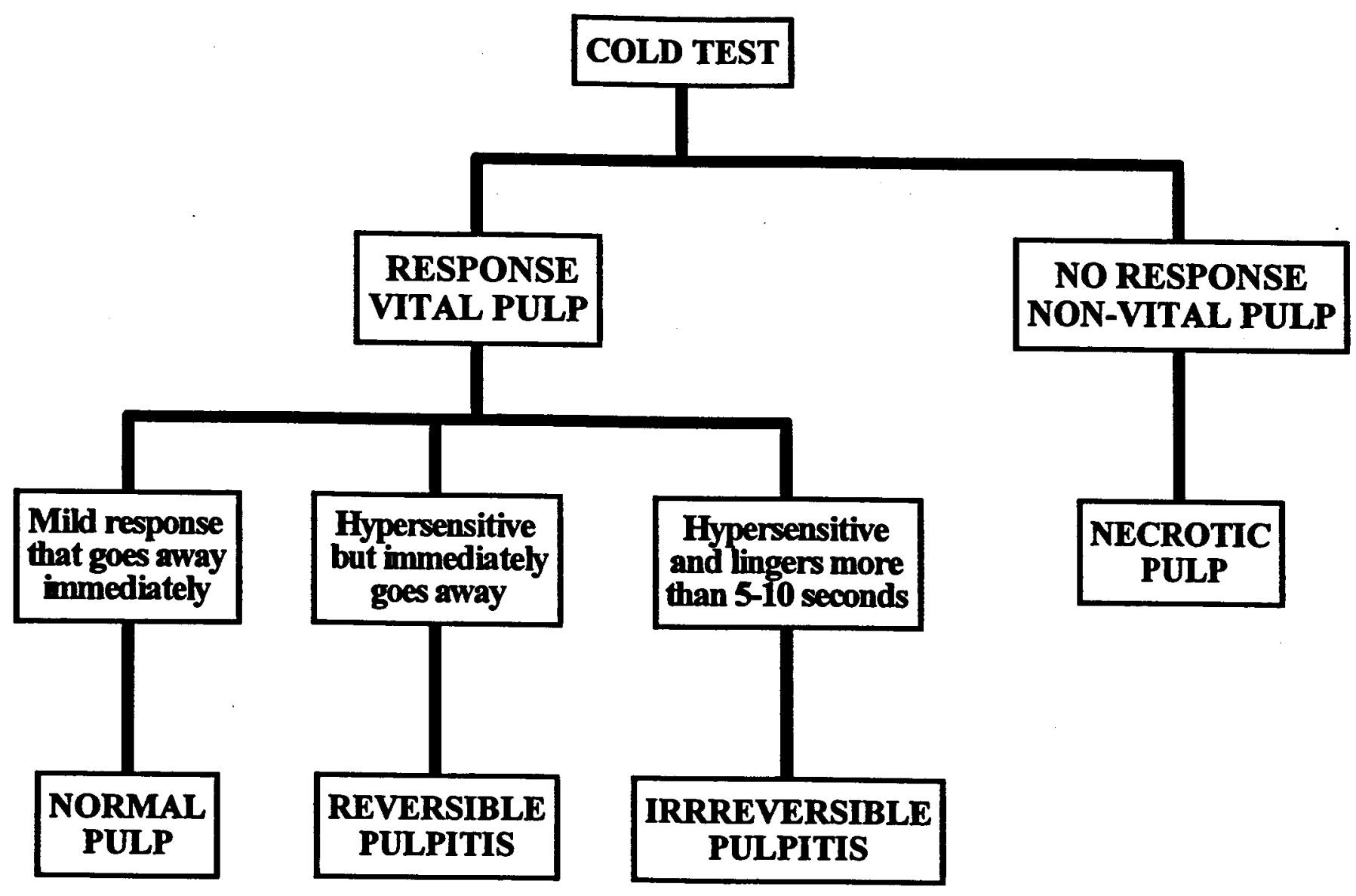




\section{Periapical Diagnosis}

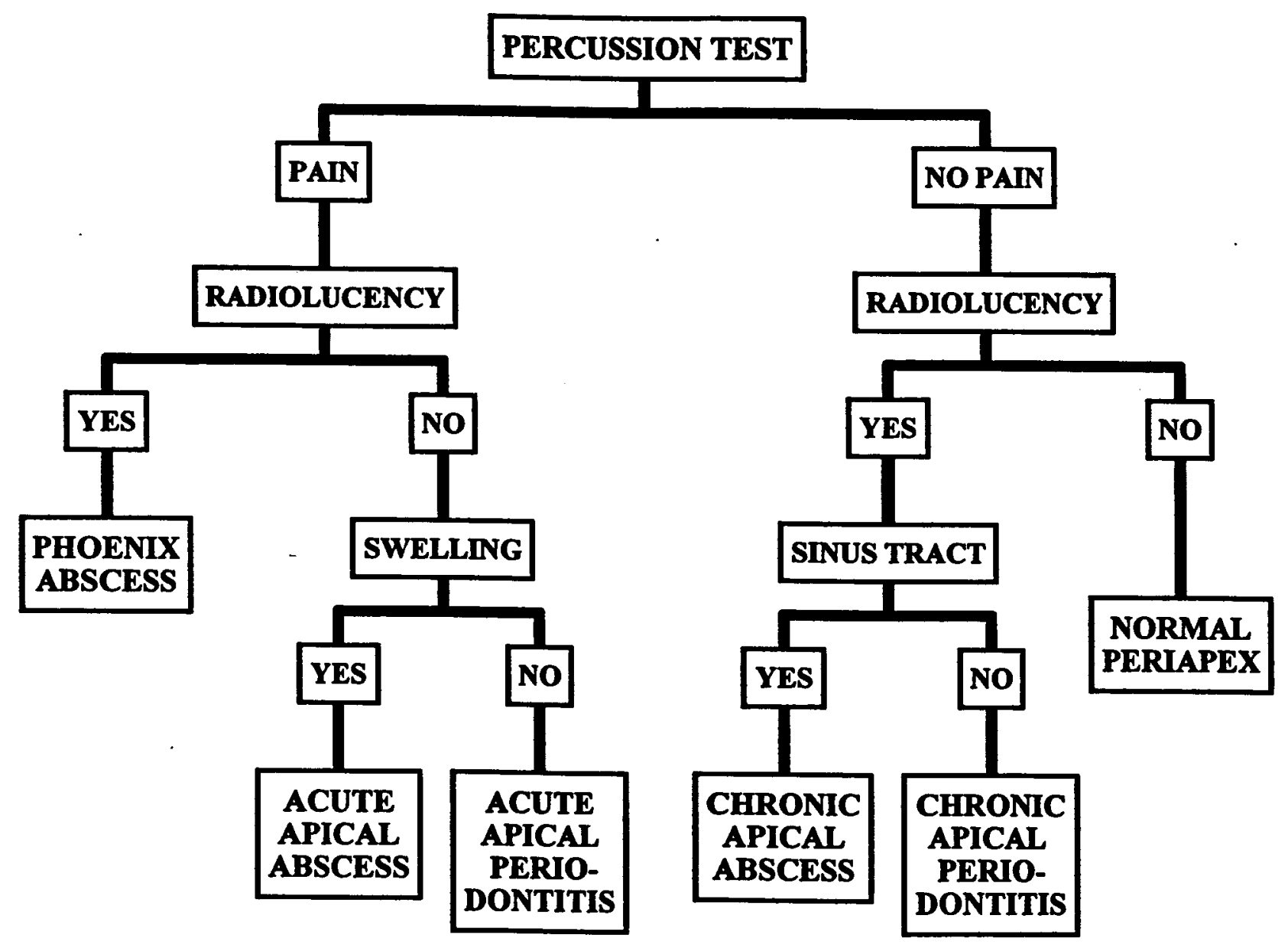


APPENDIX F

Medication Schedule 


\section{Medication Schedule}

\begin{tabular}{|c|c|}
\hline Subject & Medication \\
\hline 1 & 0 \\
\hline 2 & 2 \\
\hline 3 & 1 \\
\hline 4 & 2 \\
\hline 5 & 0 \\
\hline 6 & 1 \\
\hline 7 & 2 \\
\hline 8 & 0 \\
\hline 9 & 1 \\
\hline 10 & 0 \\
\hline 11 & 1 \\
\hline 12 & 0 \\
\hline 13 & 0 \\
\hline 14 & 2 \\
\hline 15 & 2 \\
\hline 16 & 2 \\
\hline 17 & 0 \\
\hline 18 & 2 \\
\hline 19 & 1 \\
\hline 20 & 1 \\
\hline 21 & 1 \\
\hline
\end{tabular}

$0=$ Placebo $; 1=$ Ibuprofen $; 2=$ Etodolac 


\section{ABSTRACT \\ THE EFFECTIVENESS OF PROPHYLACTIC ETODOLAC ON POST-ENDODONTIC PAIN}

\section{By Eric R. Menke}

The purpose of this clinical study was to determine if prophylactic oral administration of etodolac would significantly reduce post-endodontic pain, when compared to ibuprofen and a placebo.

Thirty-six patients requiring conventional root canal therapy were evaluated. Patients consented to single blind oral administration of either $400 \mathrm{mg}$ of etodolac, 600 mg of ibuprofen, or a placebo, prior to conventional root canal therapy. Pain evaluation was completed on a pain survey that consisted of visual analog scales at the following time intervals; initial, immediately after, 4 hours, 8 hours, 12 hours, 24 hours, 48 hours, and 72 hours after initiation of root canal therapy. Each patient was given an additional dose of the test medication and was instructed to record the time it was taken, if necessary, on the pain survey.

The results showed that a significant difference was found for ibuprofen's ability to reduce post-endodontic pain at 4 and 8 hours after initiation of root canal therapy, when compared to etodolac and a placebo (4 Hours P-value $=0.0111 ; 8$ Hours P-value $=$ 0.0397). A significant difference was also found for the periapical diagnosis and the need 
for additional medication after completion of root canal therapy. A periapical diagnosis of an Acute Apical Periodontitis or a Phoenix Abscess significantly required additional medication after root canal therapy compared to a Normal Periapex, Chronic Apical Periodontitis, and a Chronic Apical Abscess $(\mathrm{P}-\mathrm{value}=0.0077)$.

Two conclusion were found; 1) $600 \mathrm{mg}$ of ibuprofen was superior to $400 \mathrm{mg}$ of etodolac and superior to a placebo for post-endodontic pain at 4 and 8 hours after initiation of root canal therapy and 2) patients presenting with a periapical diagnosis of an Acute Apical Periodontitis or a Phoenix Abscess are more likely to require additional medication for post-endodontic pain compared to a periapical diagnosis of a Normal Periapex, Chronic Apical Periodontitis, or a Chronic Apical Abscess. 


\section{CURRICULUM VITAE}

\section{BIOGRAPHICAL DATA}

Name:

Date of Birth:

Place of Birth:

Spouse:

II. EDUCATION

Miami University

The Ohio State University

West Virginia University
Eric Richard Menke

July 4, 1971

Columbus, Ohio

Christine Haley Menke
B.S. Exercise Science

1993

D.D.S.

Masters of Science
1997

1999 